Some thesis-submission complications are beyond the powers of even the most organized students to do anything about. If your lab burns down, taking your experiment and results with it, no amount of planning or preparation will help. However, examiners are not looking to fail candidates, and will generally take pity on those who have genuinely had bad luck. "There are always the acts of God-type events," says Shinton. "Funders and institutions are always going to look sympathetically at such cases."

Given the hard work and sacrifice required to gain a $\mathrm{PhD}$ and the wide variety of things that can go wrong, some might wonder whether it is worth it. The answer will vary on a case-by-case basis, depending partly on individuals' career paths and other goals. Some who advise $\mathrm{PhD}$ candidates say it is important to bear in mind the scope for personal development that gaining the prized qualification can bring.

Mewburn, for example, thinks that completing her $\mathrm{PhD}$ on the use of hand gestures in the teaching of architecture gave her the confidence to take on a number of complex professional projects. She uses the Finnish word 'sisu' to describe the grim determination in the face of adversity that individuals must go through to get their PhDs. "The process of doing a $\mathrm{PhD}$ shows you what you are capable of," she says. "If it is done well, it can give you an intense sense of achievement and power. "Plus," Mewburn adds, "it's nice when people call you 'doctor' on aeroplanes." -

Nic Fleming is a freelance writer based in Bristol, UK.

\title{
COLUMN
}

\section{Teaching is a privilege}

\section{Scientists should embrace teaching responsibilities, advises Sarah A. Gagliano Taliun.}

“A postdoc is just like a faculty position minus all the hassles of teaching," a visiting professor told me and a handful of postdoctoral colleagues during an informal networking lunch earlier this year.

I disagree with this attitude towards education. Teaching at the university level is not and should not be considered a burden or chore that just needs to be done. It is a crucial part of academia, and it is essential that mentors portray it as such. We all want to do scientifically sound research, and, without question, we should all strive to be effective teachers. Through teaching, researchers are responsible for the education of the next generation of scientists, who will use their own unique ideas and skill sets to advance their fields.

In both my $\mathrm{PhD}$ programme and my postdoctoral fellowship, I have sought out teaching opportunities because I see them as an opportunity for enrichment, rather than a hindrance. I have supervised undergraduates during an intensive summer research programme, and have mentored numerous students doing research. Also, as a postdoctoral fellow, I have co-instructed several graduate-level courses. Each time I find myself in a teaching role, I try to do it better.

I work to improve the delivery of the lesson, to induce a deeper level of critical thinking through my exam questions and to incorporate new teaching strategies to meet the needs of a wider range of learners. I learn from my students. Through their fresh perspectives, I am able to rethink my research as well as the current state of the field and where it is going. For example, questions from my students helped me to reconsider the accepted threshold for 'genomewide significance' and how it might change.

From my experiences, I have three pieces of advice to help researchers become better teachers.

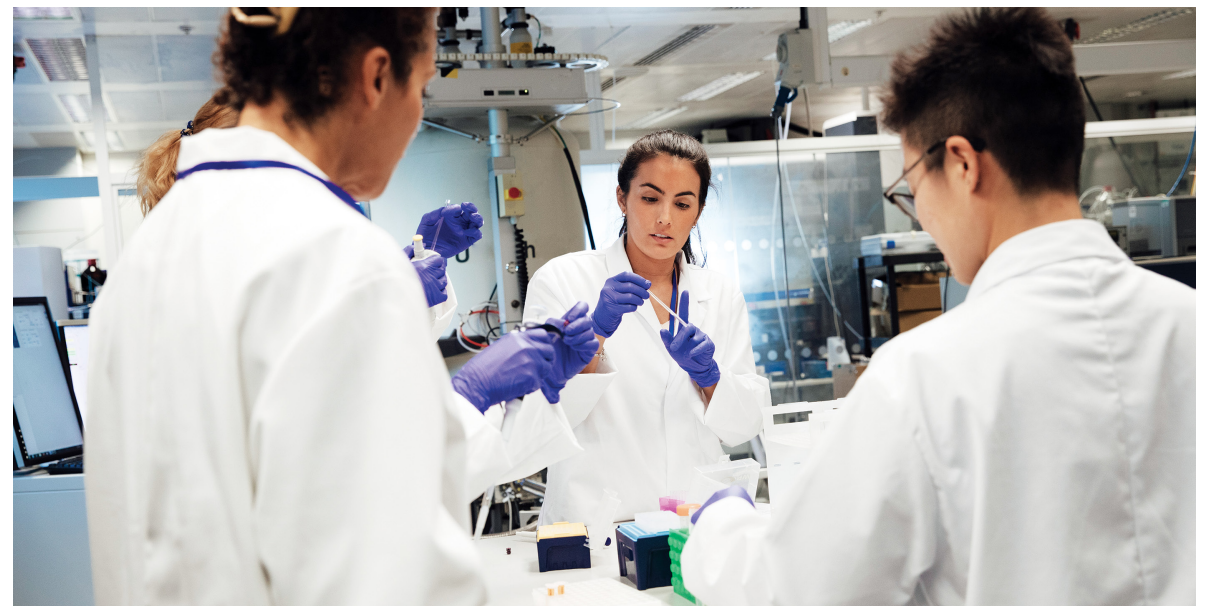

Teaching and research are both integral parts of science.

Approach teaching with an open mind. The predominant attitude in the sciences needs to shift: teaching is not a waste of prized research time. Certainly, there are academics who value the responsibility of teaching, but this group needs to become the majority.

Reach out for support when planning a class. Most of us are not innate teachers, just as most of us are not innate researchers. As with developing any skill, learning to teach is a process that requires trial and error and lots of practice. To this end, many universities offer professional-development programmes designed for graduate students, postdoctoral fellows or faculty members to improve teaching practices and techniques in the classroom, the laboratory and beyond. It is never too early or too late to work on developing these skills, many of which are applicable outside the classroom, such as when mentoring students who are doing research or giving oral presentations.

Prepare thoroughly so that the content and flow of the lesson is concise and coherent, and is tailored to the audience. This preparation takes time, but by doing it you will at the same time develop new ideas on presenting your own research (through verbal, written or visual means) to non-specialists, thus broadening its reach.

I am working towards a career in academia and am aware of the ever-increasing pressures on researchers to publish in high-quality journals, secure funding and present at conferences. Teaching is often lower down on this list of priorities. I feel that science needs to rethink its positioning.

Teaching at the university level should not be seen as a hassle in academia, but rather as a skill to be developed and a responsibility to be taken seriously. Teaching does not have to decrease research productivity - it can greatly enhance research if we allow it to. -

Sarah A. Gagliano Taliun is a postdoctoral research fellow in biostatistics at the University of Michigan in Ann Arbor. 